2017-05

\title{
A dynamic IS-LM-X model of exchange rate adjustments and movements
}

\author{
Almshri, Hamed
}

http://hdl.handle.net/10026.1/8555

10.1016/j.inteco.2016.12.001

International Economics

Elsevier BV

All content in PEARL is protected by copyright law. Author manuscripts are made available in accordance with publisher policies. Please cite only the published version using the details provided on the item record or document. In the absence of an open licence (e.g. Creative Commons), permissions for further reuse of content should be sought from the publisher or author. 


\title{
A dynamic IS-LM-X model of exchange rate adjustments and movements
}

\author{
Peijie Wang \\ Plymouth Business School, University of Plymouth \\ Institute of World Economy, Fudan University
}

\begin{abstract}
This paper contributes to the literature through developing a model of exchange rate adjustments in a dynamic IS-LM-X analytical framework. Our new model, in particular, a) makes the IS-LM model dynamic; b) endogenizes the exchange rate and price variables and; c) extends the dynamic IS and LM components into the external sector in an open economy that evolves over time. The effect of a change in monetary policy on the exchange rate is evaluated and the trajectory towards its new long-run equilibrium level is projected. These are in contrast to the traditional monetary models of exchange rate determination and adjustments that play primarily with the LM component of the IS-LM framework in discrete steps. Effects of interest rate parity and purchasing power parity are then scrutinized, ranging from the short-term to the long-run continuously. The study has profound policy implications, especially in an era of quantitative easing.
\end{abstract}

Key words: exchange rate, monetary policy, interest rate parity, purchasing power parity

JEL No: F31, F37 


\section{Introduction}

The foreign exchange market is crucial to international economic co-operations. It facilitates international trade and transactions. Nonetheless, disturbances generated in one part of this interlinked global economy can also be transmitted and magnified through the foreign exchange market as one of the direct and major channels to impact on the financial markets around the world. Exchange rate behavior, which is central to constitution of an orderly foreign exchange market, should therefore be scrutinized to better our understanding of exchange rate determination and adjustments.

The present study puts forward a model of exchange rate adjustments and movements in a dynamic IS-LM-X analytical framework, where $\mathrm{X}$ denotes external sector. It firstly makes the IS-LM model dynamic, and then endogenizes the exchange rate and price variables. That being said, it extends the dynamic IS and LM components into the external sector in an open economy that evolves continuously. Effects of interest rate parity (IRP) and purchasing power parity (PPP) can be scrutinized in this framework as time goes by. The model sets no new equilibrium exchange rate explicitly, which replaces its rational agents with real role-players. The goods price moves and adjusts naturally, corresponding with the movements and adjustments in the interest rate and the exchange rate. The rest of the paper is organized as follows. The next section presents the construct and paradigm of this study. Section 3 elaborates on the features of the model and Section 4 demonstrates the evolution path of exchange rate adjustments and movements in the dynamic IS-LM-X framework. Section 5 provides an illustrating case, while Section 6 summarizes this study.

\section{Prior studies}

Exchange rate modeling seems to be a thing of obsession in the 1960s and 1970s, when theoretical models of exchange rate determination burgeoned. Famously these include 
Mundell-Fleming (Mundell 1963; Fleming 1962), Frenkel (1976), Dornbusch (1976), Frankel (1979) and Branson (1976). The global economic environment has changed profoundly however, in particular the exchange rate regimes, which matters much to exchange rate behavior. The breakdown of the Bretton Woods system marked the end of fixed exchange rate regimes. In August 1971, US President Richard Nixon announced the "temporary" suspension of the dollar's convertibility into gold, and the major currencies began to float against each other by March 1973. Although the monetary models of Frenkel (1976) and Dornbusch (1976), the real interest rate differential model of Frankel (1979) and the portfolio balance approach by Branson (1976) appeared some three years into the floating system, the work and thinking were fixed to the fixed exchange rate regime and analytical framework. Due to their prominence however, these models have been tested with floating exchange rate data time and again. Against this backdrop, a considerable number of empirical studies have been carry out with the initial intention to back these models and verify them empirically, only to generate unsatisfactory empirical results or results that are contradictory to what the models dictated. For instance in testing Dornbusch's (1976) overshooting hypothesis, Levin (1994) finds a monetary expansion that initially lowers interest rates can produce either overshooting or undershooting of the exchange rate. Cavaglia (1991) also contradicts the exchange rate overshooting hypothesis. Frankel (1979) has proposed a real interest rate differential model as an alternative to the flexible price monetary model and Dornbusch's sticky price monetary model. His findings reject both models based on the results of coefficient restrictions. Following Frankel (1979), the results in Meese and Rogoff (1988) also fail to lend support to the functional relationship between real exchange rates and real interest rate differentials implied by the Dornbusch model as well as the Frankel model. In addition to the argument on overshooting or undershooting, a number of studies have indicated that the overshooting model is outperformed by random walk 
models in exchange rate forecasts. Hwang's (2003) results suggest that the random walk model outperforms the Dornbusch and Frankel models at every forecasting horizon. Similarly, Zita and Cupta (2008) find that naïve models outperform the Dornbusch model. Furthermore, many have departed far away from the original setting of immediate responses upon an increase in money supply. For example, Verschoor and Wolff (2001) investigate the effect at the 3-, 6-, and 12-month horizons to find out whether exchange rates overshoot using the Mexican data. Mussa (1982) has inspected exchange rate movements over 6 months to see if the currency over deprecated. Such departure is typified to a magnified degree by Heinlein and Krolzig (2012) who have detected delayed overshooting 2-3 years after a monetary policy shock. It has become obvious that these models of exchange rate movement and determination, in particular the overshooting hypothesis, do not fit into the contemporary international economic setting, and therefore do not perform under the circumstances. This calls for new models and new modeling approaches appropriate for the exchange regimes well after the dismantling of the Bretton Woods system. The present study is one of the attempts in search for solutions.

\section{The model}

We propose a model exchange rate adjustments and movements in a dynamic IS-LM-X analytical framework to deal with an external sector in an open economy. The IS-LM model has received much criticism after its early popularity. It is static, and it treats government expenditure, tax revenue and exchange rates as exogenous on the incomeinterest rate plane. While Fleming (1962) and Mundell (1963) extend the IS-LM framework on the income-interest rate plane by incorporating BP curves on the incomeexchange rate plane, the Mundell-Fleming model is in a discrete short-term and long-run 
two-step framework. The dynamic IS and LM components in our model evolve over time, ranging from the short-term to the long-run continuously.

\subsection{The setting and dynamics}

Our new setting involves an exchange rate-interest rate plane, in addition to an incomeinterest rate plane where IS and LM curves are located. Thus our analytical framework endogenizes the exchange rate and price variables with a dynamic IS component. Start with the national account identity:

$$
S(t)+T(t)-I(t)=G(t)+T B(t)
$$

where $S(t)$ is savings, $T(t)$ is tax, $I(t)$ is private investment, $G(t)$ is government spending and $\operatorname{TB}(t)$ is trade balance. It is conventionally assumed that: savings are an increasing function of output and interest rate; private investment is an increasing function of output while a decreasing function of interest rate; tax is an increasing function of output; and trade balance is a decreasing function of output and an increasing function of real exchange rate. These relationships are shown as follows:

$$
\begin{gathered}
S\{Y(t), r(t)\}=Y(t)^{a_{1}}[1+r(t)]^{\gamma_{1}} \\
T\{Y(t)\}=Y(t)^{a_{2}} \\
I\{Y(t), r(t)\}=Y(t)^{a_{3}}[1+r(t)]^{-\gamma_{2}} \\
T B\{Y(t), q(t)\}=Y(t)^{a_{4}} \exp \left\{\beta \operatorname{Ln}[Q(t)]+\delta \frac{d(\operatorname{Ln}[Q(t)])}{d t}\right\}
\end{gathered}
$$

where $Y(t)$ is output, $r(t)$ is real interest rate, $Q(t)$ is real exchange rate; $a_{1}, a_{2}, a_{3}, a_{4}$, $\zeta_{1}, \zeta_{2}, \beta$ and $\delta$ are positive coefficients. In empirical modeling, the use of the real exchange rate is a test with absolute PPP, while the use of changes in the real exchange rate is a test with relative PPP. Therefore, we propose in equation 2(d) that, trade balance is affected by not only the exchange rate but also the velocity of change in exchange 
rates. Different people may have different views on whether a currency is undervalued or overvalued and the extent to which the currency is undervalued/ overvalued, and adoption of different measures would lead to assigning different values to the real exchange rate. Nevertheless, changes in real exchange rates would send out a signal as to the currency's depreciation or appreciation, thus having impact on trade balance. In a recent survey by International Monetary Fund (IMF), it has been documented that exchange rate changes were associated with growing net exports for the depreciating countries, a development that is part of the natural adjustment process to differential growth rates that flexible exchange rates promote. 'Historical experience in advanced and emerging market and developing economies suggests that exchange rate movements typically have sizable effects on export and import volumes. A 10 percent real effective depreciation in an economy's currency is associated with a rise in real net exports of, on average, 1.5 percent of GDP, with substantial cross-country variation around this average' (International Monetary Fund 2015). Auboin and Ruta (2011) have conducted a comprehensive review of the literature and summarized that 'A number of papers have looked at the empirical relationship between exchange rate devaluation and export surges. ..., find that depreciation encourages exports for most countries'. They have further remarked 'The policy and academic debate shifted somewhat at this time, away from the effects on trade of exchange volatility towards the effects of sustained exchange rate depreciation or perceived exchange rate misalignments', indicating the role of human perception played in achieving or failing to achieve a consensus on right exchange rate levels.

The real exchange rate in logarithms, by definition, is:

$$
q(t)=\operatorname{Ln}[Q(t)]=e(t)-p(t)+p^{f}
$$


where $e(t)$ is nominal exchange rate, $p(t)$ is price of goods and $p^{f}$ is foreign price of goods, all in logarithms. Bringing equations (2a), (2b), (2c) and (2d) into equation (1) yields:

$$
Y(t)^{a}[1+r(t)]^{r} \exp \left\{-\beta \operatorname{Ln}[Q(t)]-\delta \frac{d(\operatorname{Ln}[Q(t)])}{d t}\right\}=G(t)
$$

where $a>0$ is an aggregate of $a_{1}, a_{2},-a_{3}$ and $a_{4}$, and $\gamma>0$ is an aggregate of $\gamma_{1}$ and $\gamma_{2}$. The logarithmic form of equation (3) is derived as:

$$
a y(t)+\gamma r(t)-\beta q(t)-\delta \frac{d q(t)}{d t}=g(t)
$$

where $a=\left(a_{1}-a_{2}+a_{3}+a_{4}\right)>0$ and $\gamma=\left(\gamma_{1}+\gamma_{2}\right)>0$. The LM component is conventionally adopted, being derived from the liquidity of money equation:

$$
\frac{M(t)}{P(t)}=L\{r(t), Y(t)\}=\frac{Y(t)^{\eta}}{[1+r(t)]^{\lambda}}
$$

where $M(t)=M(t)^{d}=M(t)^{s}$ is demand for money that is equal to money supply in equilibrium, and $\eta$ and $\lambda$ are positive coefficients. Taking the logarithmic transformation leads to:

$$
m(t)-p(t)=\eta y(t)-\lambda r(t)
$$

All the variables in the above equation are in logarithms. Equation (4') and equation (5') constitute a dynamic IS-LM system. All the variables can be endogenous in theory at this stage, while certain variables can become exogenous or remain constant under various circumstances, given the orientation of modeling or policy analysis.

The IS-LM system on the income-interest rate plane treats the real exchange rate, alongside demand for money and government expenditure, as exogenous or as a policy instrument for altering the level of interest rates and income. We extend and map the ISLM system to the exchange rate-interest rate plane, so the real exchange rate, as well as the nominal exchange rate and price, becomes endogenous. We depart further from the 
conventional static IS-LM analysis. Given an increase in money supply of $d m$, the interest rate would be reduced by $\frac{d m}{\lambda}$ in equation $\left(5^{\prime}\right)$, with no change in price and income. Correspondingly in equation (4'), it is required that $\left[\beta q(t)+\delta \frac{d q(t)}{d t}\right]=-\frac{\gamma}{\lambda} d m$, which rectifies one of the major defects in the static IS-LM model. The following remarks elucidate the issue.

In the static IS-LM model where $\delta=0, q(t)$ is required to be reduced by $\frac{\gamma}{\beta \lambda} d m$, given no change in income and government spending. This in turn indicates that $e(t)$ is reduced by the same degree, given no immediate change in price. A reduction in $q(t)$ or $e(t)$ means appreciation of the domestic currency, which is implausible. We question this judiciousness. A domestic interest rate that is lower than the world level of interest rates would result in the domestic currency to appreciate, which takes time. For example and assuming that the domestic interest rate remains unchanged at this lower level for one year, it would take one year for the domestic currency to appreciate by $\frac{d m}{\lambda}$ according to interest rate parities. In our model with $\delta>0$, it is not required for $q(t)$ to be reduced by $\frac{\gamma}{\beta \lambda} d m$ immediately to attain the new temporary equilibrium in the goods market, $q(t)$ could increase as well. The shift is realized by the velocity of exchange rate changes, which makes the system dynamic meanwhile. Bringing equation (3) into equation (4) leads to:

$$
\beta e(t)+\delta \frac{d e(t)}{d t}-\gamma r(t)=\beta p(t)+\delta \frac{d p(t)}{d t}-\beta p^{f}+a y(t)-g(t)
$$

The dynamic equilibrium IS-LM-X model represented by equation (6) is illustrated in Figure 1. The right side panel is the traditional IS-LM analysis on the income-interest 
rate plane. MX is the LM curve mapped to the exchange rate-interest rate plane. When mapping the LM curve onto the exchange rate-interest rate plane, the curve is horizontal since the exchange rate is not a variable for the LM curve. IX is the IS curve mapped to the exchange rate-interest rate plane. $r^{*}$ is the equilibrium interest rate that is set to equal the world level of interest rates. The curve is flatter when $r_{t}$ is far away from $r^{*}$ and steeper when $r(t)$ is closer to $r^{*}$, reflecting the IRP effect. The arrows on the IX curve indicate that the interest rate and exchange rate revert to their equilibrium positions. When $r(t)<r^{*}$, the domestic currency would appreciate or the exchange rate would decrease while the domestic interest rate rises and reverts to the world level of interest rates. When $r(t)>r^{*}$, the domestic currency would depreciate or the exchange rate would increase while the domestic interest rate falls and reverts to the world level of interest rates. Suppose that the LM curve shifts to LM', the IS curve would shift to IS'. Correspondingly, the MX curve moves to MX', and the IX curve moves to IX'. Note that a shift of the IX curve is by changes in $p(t), y(t), g(t)$ and $\frac{d p(t)}{d t}$, to be specified later.

\section{$\{$ Figure 1\}}

\subsection{The solution}

So far, money supply can be endogenous or exogenous, as on either side of the debate on whether money supply is endogenous or exogenous in the literature. We advocate that whether it is endogenous or exogenous depends on the circumstances. Under the circumstance of this study, money supply is endogenous at first, in response to the need of increasing or reducing money supply in the economy. Once decided and implemented, 
it remains exogenous and constant until the next monetary policy change, which is the assumption for the dynamics and solution of the model developed thereafter. Assume that the system is in equilibrium at $t=0$, with $m(0)=\bar{m}, p(0)=\bar{p}, y(0)=\bar{y}, r(0)=\bar{r}$, $e(0)=\bar{e}$ and $g(0)=\bar{g}$; and the equilibrium interest rate is set to equal the world level of interest rates $\bar{r}=r^{*}$. Given an increase in money supply at time $O^{+}$, the money market equilibriums before and after the increase in money supply are:

$$
\begin{gathered}
m(0)-p(0)=p y(0)-\lambda r(0) \\
m(0)+d m-p\left(0^{+}\right)=p y\left(0^{+}\right)-\lambda r\left(0^{+}\right)
\end{gathered}
$$

The domestic interest rate, corresponding to the monetary expansion, is reduced by:

$$
r\left(0^{+}\right)-r(0)=-\frac{d m}{\lambda}
$$

according to equation (5'), since the price is fixed in the short-term and output is not supposed to be affected, i.e., $p\left(0^{+}\right)=p(0), y(t) \equiv y(0)$. The domestic interest rate assumes a function form with which it rises gradually in reverting ${ }^{1}$ to the world level of interest rates at $\operatorname{speed} \varphi$ :

$$
r(t)=r^{*}-\frac{d m}{\lambda} e^{-\varphi t}
$$

It stipulates that $r(t)=r^{*}-\frac{d m}{\lambda}$ at $t=0^{+}$as a consequence of the increase in money supply signified by equation (7), then $r(t)$ rises gradually at speed $\varphi$ and $r(t)=r^{*}$ when $t \rightarrow \infty$. Then the price of goods rises in the same way as follows:

$$
p(t)=p(0)+\left(1-e^{-\varphi t}\right) d m
$$

for the money market to clear continuously. It stipulates that $p(t)=p(0)$ at $t=0^{+}$as the price does not rise immediately; and $p(t)=p(0)+d m$ when $t \rightarrow \infty$ which indicates $p(t)-p(0)=d m$, i.e., the increase in goods price is equal to the increase in money supply in the long-run when the effect of the increase in money supply on the 
price is fully taken. Conforming to the Fisher effect, the price rises at the same speed $\varphi$ as the interest rate. The goods market equilibriums before and after the increase in money supply are:

$$
\begin{gathered}
\beta e(0)-\gamma r(0)=\beta p(0)-\beta p^{f}+a y(0)-g(0) \\
\beta e(t)+\delta \frac{d e(t)}{d t}-\gamma r(t)=\beta p(t)+\delta \frac{d p(t)}{d t}-\beta p^{f}+a y(0)-g(0)
\end{gathered}
$$

with $y(t) \equiv y(0)$ and $g(t) \equiv g(0)$. Subtracting equation (6a) from equation (6b) yields:

$$
\delta \frac{d e(t)}{d t}=-\beta[e(t)-e(0)]+\gamma\left[r(t)-r^{*}\right]+\beta[p(t)-p(0)]+\delta \frac{d p(t)}{d t}
$$

There is feedback from the exchange rate itself, and indirect feedback through the interest rate and price loops, shown in the above equation. Given equation (8), equation (9) and $\frac{d p(t)}{d t}=\varphi e^{-\varphi t} d m$, the above can be re-arranged to:

$$
\begin{aligned}
& \delta \frac{d e(t)}{d t}=-\beta e(t)+\beta e(0)-\frac{\gamma}{\lambda} e^{-\varphi t} d m+\beta\left(1-e^{-\varphi t}\right) d m+\delta \varphi e^{-\varphi t} d m \\
& =-\beta e(t)+\beta e(0)+\beta d m+\left(\delta \varphi-\beta-\frac{\gamma}{\lambda}\right) e^{-\varphi t} d m
\end{aligned}
$$

which is a first-order linear non-autonomous constant parameter differential equation and has a general solution of:

$$
\begin{aligned}
& e(t)=e^{\int\left(-\frac{\beta}{\delta}\right) d t}\left\{\int\left[\frac{\beta}{\delta} e(0)+\frac{\beta}{\delta} d m+\frac{1}{\delta}\left(\delta \varphi-\beta-\frac{\gamma}{\lambda}\right) e^{-\varphi t} d m\right] e^{-\int\left(-\frac{\beta}{\delta}\right) d t} d t+C\right\} \\
& =e(0)+d m-\frac{\frac{\beta}{\delta}-\varphi+\frac{\gamma}{\delta \lambda}}{\frac{\beta}{\delta}-\varphi} d m \cdot e^{-\varphi t}+C e^{-\frac{\beta}{\delta} t}, \forall t \geq t\left(0^{+}\right)
\end{aligned}
$$

$C$ is solved by taking the boundary conditions into consideration: 


$$
\begin{aligned}
& C=e\left(0^{+}\right)-e(0)+\left(\frac{\frac{\beta}{\delta}-\varphi+\frac{\gamma}{\delta \lambda}}{\frac{\beta}{\delta}-\varphi}-1\right) d m \\
& =e\left(0^{+}\right)-e(0)+\left(\frac{\frac{\gamma}{\delta \lambda}}{\frac{\beta}{\delta}-\varphi}\right) d m
\end{aligned}
$$

Conclusively, the exchange rate moves and evolves as follows:

$$
\begin{aligned}
& e(t)=e(0)+d m+\left[e\left(0^{+}\right)-e(0)\right] e^{-\frac{\beta}{\delta} t}+\left(\frac{\frac{\gamma}{\delta \lambda}}{\frac{\beta}{\delta}-\varphi}\right) d m \cdot e^{-\frac{\beta}{\delta} t}-\frac{\frac{\beta}{\delta}-\varphi+\frac{\gamma}{\delta \lambda}}{\frac{\beta}{\delta}-\varphi} d m \cdot e^{-\varphi t} \\
& =e(0)+\left(1-e^{-\frac{\beta}{\delta} t}\right) d m+\left[e\left(0^{+}\right)-e(0)\right] e^{-\frac{\beta}{\delta} t}+\frac{\frac{\beta}{\delta}-\varphi+\frac{\gamma}{\delta \lambda}}{\frac{\beta}{\delta}-\varphi} d m\left(e^{-\frac{\beta}{\delta} t}-e^{-\varphi t}\right), \forall t \geq t\left(0^{+}\right)
\end{aligned}
$$

It is apparent that $e(t)=e(0)+d m, t \rightarrow \infty$. The features of the model and each of its elements are discussed in the next section.

\subsection{Rational and constrained expectations}

The above analysis has implicitly incorporated the formation of expectations that is constrained and rational. According to IRP, the expected changes in exchange rates equal to the interest rate differentials:

$$
\begin{aligned}
& E\left[\frac{d e(t)}{d t}\right]=i(t)-i^{*}=r(t)+\pi(t)-r^{*}-\pi^{*} \\
& =r(t)-r^{*}+\pi(t)-\pi^{*}
\end{aligned}
$$

or:

$$
\begin{aligned}
& E[d e(t)]=\left[i(t)-i^{*}\right] d t=\left[r(t)+\pi(t)-r^{*}-\pi^{*}\right] d t \\
& =\left[r(t)-r^{*}+\pi(t)-\pi^{*}\right] d t
\end{aligned}
$$

where $i(t)$ is nominal interest rate, $i^{*}$ is world nominal interest rate, $\pi(t)$ is inflation rate, $\pi^{*}$ is world inflation rate ${ }^{2}$. Equation (15) is IRP as well as international Fisher effect 
(IFE). It is rational expectations, being constrained by IRP and IFE with both short-term and long-run effects and implications. However, while equation (15) constrains a rational expectations formation in the money market, the evolution paths of real and nominal interest rates and inflation are further constrained and regulated by the relationships in the goods markets in the dynamic IS-LM system. The trajectory portrayed by equation (15) should be the same as the trajectory of equation (11) and its solution equation (14) under rational and constrained expectations. The unstructured IRP and IFE of equation (15) interact with and in the structured dynamic IS-LM system to offer a rational and constrained solution.

\section{The features of the model}

We focus on the evolution path of the exchange rate after the shock in this study, and leave $e\left(0^{+}\right)$unsolved and subject it to actual figures. Findings in the empirical literature imply that $e\left(0^{+}\right)$is not predictable or can't be modeled, as indicated in Section 2 . The second term on the right hand side of equation (14) increases gradually from 0 at $t=0$ to $d m$ when $t \rightarrow \infty$. The third term is the initial shock effect, which fades away eventually as $t \rightarrow \infty$. Given the initial effect is domestic currency depreciation to varied degrees, as evident in the above reviewed studies, $e\left(0^{+}\right)-e(0)>0$. Therefore, the third term decreases over time. The fourth term starts at 0 at $t=0$ and approaches 0 when $t \rightarrow \infty$. It is concave or has a minimum value, which can be proved as follows. $\frac{\beta}{\delta}-\varphi+\frac{\gamma}{\delta \lambda}>0$, given that the elasticity or sensitivity parameters are smaller than unity. Then, $\frac{\frac{\beta}{\delta}-\varphi+\frac{\gamma}{\delta \lambda}}{\frac{\beta}{\delta}-\varphi}>0$ if $\frac{\beta}{\delta}>\varphi$; and $\frac{\frac{\beta}{\delta}-\varphi+\frac{\gamma}{\delta \lambda}}{\frac{\beta}{\delta}-\varphi}<0$ if $\frac{\beta}{\delta}<\varphi$. So, it is required to prove that 
$e^{-\frac{\beta}{\delta} t}-e^{-\varphi t}$ is concave or has a minimum for $\frac{\beta}{\delta}>\varphi$ and $e^{-\frac{\beta}{\delta} t}-e^{-\varphi t}$ is convex or has a maximum for $\frac{\beta}{\delta}<\varphi$. In the case when $\frac{\beta}{\delta}=\varphi, \operatorname{Lim}_{\varphi \rightarrow \frac{\beta}{\delta}}\left(\frac{e^{-\frac{\beta}{\delta} t}-e^{-\varphi t}}{\frac{\beta}{\delta}-\varphi}\right)=-t \cdot e^{-\varphi t}=-t \cdot e^{-\frac{\beta}{\delta} t}$. Technical proofs are provided in Appendix A. Given the proofs, the fourth term decreases first and then increases, featuring initial appreciation of the domestic currency after the monetary shock.

\section{\{Figure 2\}}

Finally, we inspect the overall pattern in exchange rate evolutions, combining the features of individual elements. The domestic currency would appreciate initially after the shock, and then depreciate towards its new long-run equilibrium rate. The exchange, starting at $e_{0^{+}}$, decreases and reaches its minimum $e_{\min }$ at $t_{m}$, shown in Appendix B. That is, the domestic currency would appreciate initially after the shock, and then depreciate towards its new long-run equilibrium level $e_{0}+d m$. These are exhibited in Figure 2 with the patterns in each element of equation (14) and the overall pattern in exchange rate adjustments and evolutions.

The above demonstrated pattern of exchange rate evolution is consistent with that in a recent study of Wang (2013). Upon an increase in money supply, the interest rate falls with IRP taking effect initially, with which the currency appreciates, and then the sticky price rises gradually from the medium-term and over the long-run, in which the currency depreciates. He has demonstrated three cases that initially reversely shoots, over shoots and under shoots respectively. All of them make reverse movements after the initial shock in the short-term, be the initial response overshooting, undershooting or 
reverse shooting. Unlike Wang (2013) who assumes a short-term exchange rate target in addition to a long-run equilibrium exchange rate, our model sets no short-term target at all and no new long-run equilibrium exchange rate explicitly. It lets the open economy evolves itself. The design of our model is also coherent with, but extends, the joint dynamics of exchange rates and interest rates of Anderson et al. (2010) who apply the affine class of term structure models to exchange rate movements as diffusion processes. The evolution path of exchange rates in our model goes beyond the horizon when IRP effects have diminished to a negligible extent.

We then demonstrate the path of exchange rate adjustments and movements on the exchange rate-interest rate plane in the dynamic IS-LM-X framework, together with the corresponding adjustments and movements on the traditional income-interest rate plane. These are exhibited in Figure 3. With an increase in money supply of $d m$, the LM curve shifts from $\mathrm{LM}^{\mathrm{O}}$ to $\mathrm{LM}^{\mathrm{T}}$ on the right side panel, and the IS curve shifts from $\mathrm{IS}^{\mathrm{O}}$ to $\mathrm{IS}^{\mathrm{T}}$ meanwhile. Correspondingly on the left side panel, the MX curve shifts from $\mathrm{MX}^{\mathrm{O}}$ to $\mathrm{MX}^{\mathrm{T}}$, and the IX curve shifts from $\mathrm{IX}^{\mathrm{O}}$ to $\mathrm{IX}^{\mathrm{T}}$; they meet at the cross point $\mathrm{T}$. A shift of the IX curve is by changes in $p(t), y(t), g(t)$ and $\frac{d p(t)}{d t}$. With $y(0) \equiv y(0)$ and $g(t) \equiv g(0)$, the IX curve will shift only if there is a change in $p(t)$ or $\frac{d p(t)}{d t}$. Given $p\left(0^{+}\right)=p(0)$ and $\left.\frac{d p(t)}{d t}\right|_{t=t_{0^{+}}}=\varphi \cdot d m$, the IX curve shifts leftwards by $\frac{\delta \cdot \varphi \cdot d m}{\beta}$ upon the shock. Thereafter, the LM and IS curves move upwards gradually, while the domestic interest rate rises and reverts to the world level of interest rates, along the path signposted by the small arrows on the right side panel. The new cross point for the two curves is the same as the one before the change in monetary policy. Correspondingly, the MX curve moves upwards gradually; the IX curves, however, 
moves leftwards gradually until $\left.\frac{d p(t)}{d t}\right|_{t \rightarrow \infty}=0$ and $\left.p(t)\right|_{t \rightarrow \infty}=p(0)+d m$. The total distance the IX curve has traveled leftwards is $d m$ when the system has settled down at the new equilibrium point. The cross points of the corresponding MX and IX curves in their shifts exhibit the path of exchange rate adjustments and movements. The MX and IX curves meet at the cross point $\mathrm{N}$ when the system is in the new equilibrium. The shift of the IS curve on the income-interest rate plane is by changes in $\beta q(t)+\delta \frac{d q(t)}{d t}$, which can also be expressed in the nominal exchange rate and prices:

$$
\beta q(t)+\delta \frac{d q(t)}{d t}=\beta e(t)-\beta p(t)+\beta p^{f}+\delta \frac{d e(t)}{d t}-\delta \frac{d p(t)}{d t}
$$

At $t=t_{0^{+}}, e\left(0^{+}\right)-p\left(0^{+}\right)+p^{f}=e\left(0^{+}\right)-e(0)+e(0)-p(0)+p^{f}=e\left(0^{+}\right)-e(0)+q(0)$, $\frac{d e(t)}{d t}=-\frac{d m}{\lambda}$, and $\frac{d p(t)}{d t}=\varphi \cdot d m$, so the shift of the IS curve upon the shock is:

$$
\beta q(0)+\beta\left[e\left(0^{+}\right)-e(0)\right]-\delta \frac{d m}{\lambda}-\delta \varphi \cdot d m
$$

The downwards movement of the IS curve is enabled by the negative figures of $-\delta \frac{d m}{\lambda}-\delta \varphi \cdot d m$, allowing the domestic currency to depreciate upon the shock, i.e., allowing the nominal exchange rate to increase. Otherwise, $e\left(0^{+}\right)$has to be smaller than $e(0)$.

\section{\{Figure 3\}}

While $\varphi$ measures the swiftness of money market adjustments to attain the new equilibrium, $\frac{\beta}{\delta}$ reflects the dynamics in goods market adjustments in moving to the temporal equilibrium and then attaining the new equilibrium. If $\delta=0$, goods market 
adjustments respond to the level of the exchange rate only. A sizeable $\delta$ relative to $\beta$ feeds dynamics into the system - the velocity of exchange rate changes moves the goods market too. Moreover, $\delta>0$ guarantees continuity in goods market adjustments. The exchange rate would otherwise be required to jump in the wrong direction immediately. The money market parameter $\varphi$ plays a role for the IRP effect; $\varphi$ and the goods market parameters $\frac{\beta}{\delta}$ jointly play a part for the PPP effect. The domestic currency would appreciate to a greater extent and the appreciation period would last longer with a smaller $\varphi$. This is because the domestic interest rate reverts to the world level of interest rates with a slower speed, keeping more sizeable interest rate differentials for a longer time. According to equation (8) and uncovered IRP:

$$
E_{0^{+}}[e(t)]-e_{0^{+}}=\int_{\tau=0^{+}}^{t}\left[r(\tau)-r^{*}\right] d \tau=\int_{\tau=0^{+}}^{t}-\frac{d m}{\lambda} e^{-\varphi \tau} d \tau=\frac{d m}{\lambda \varphi}\left(e^{-\varphi t}-1\right), \forall t \geq t_{0^{+}}
$$

The IRP effect is greater and lasts longer with a smaller $\varphi$. Meanwhile, the domestic price would increase more slowly with a smaller $\varphi$. It takes a longer time for the exchange rate to increase by the full amount effected by the monetary expansion. In other words, it takes a longer time for the exchange rate to reach its new equilibrium rate - increase by the same percentage as the increase in money supply. Otherwise with a larger $\varphi$, the domestic currency would appreciate to a smaller extent and the IRP effect disappears more quickly. The domestic price would rise more rapidly and it takes a shorter time for the exchange rate to reach its new equilibrium rate. According to equation (14) and equation (9), the departure of the exchange rate from its pre shock equilibrium or PPP rate is: 


$$
\begin{aligned}
& q(t)=e(t)-p(t)+p^{f} \\
& =e(0)+\left(1-e^{-\frac{\beta}{\delta} t}\right) d m+\left[e\left(0^{+}\right)-e(0)\right]^{-\frac{\beta}{\delta} t}+\frac{\frac{\beta}{\delta}-\varphi+\frac{\gamma}{\delta \lambda}}{\frac{\beta}{\delta}-\varphi} d m\left(e^{-\frac{\beta}{\delta} t}-e^{-\varphi t}\right) \\
& -\left[p(0)+\left(1-e^{-\varphi t}\right) d m\right]+p^{f} \\
& =\left[e(0)-p(0)+p^{f}\right]+\left[e\left(0^{+}\right)-e(0)\right] e^{-\frac{\beta}{\delta} t}+\frac{\frac{\gamma}{\delta \lambda}}{\frac{\beta}{\delta}-\varphi} d m\left(e^{-\frac{\beta}{\delta} t}-e^{-\varphi t}\right) \\
& =q(0)+\left[e\left(0^{+}\right)-e(0)\right] e^{-\frac{\beta}{\delta} t}+\frac{\frac{\gamma}{\delta \lambda}}{\frac{\beta}{\delta}-\varphi} d m\left(e^{-\frac{\beta}{\delta} t}-e^{-\varphi t}\right), \forall t \geq t_{0^{+}}
\end{aligned}
$$

The first term on the right hand side is the pre shock equilibrium or PPP rate, which the exchange rate would revert to or reach. The second term is the initial shock effect that dies away when time goes by. The third term is concave. It starts at zero, decreases and becomes negative, and then increases to zero again. Therefore, the larger the parameter $\frac{\beta}{\delta}$ and the closer the parameters $\frac{\beta}{\delta}$ and $\varphi$, the faster the exchange rate would reach its PPP rate. Also the departure of the exchange rate from its PPP rate would be smaller during the adjustment course.

\section{A manifest illustration}

The last financial crisis has provided us with the rare opportunities to inspect the patterns in exchange rate movements following an expansionary monetary policy. The intention to expand the monetary base in most economies during the crisis period was almost solely to prevent the economy from sliding into recession or, at best, to keep the economy as it was, with the outcome of virtually every intervention being just that. The scales of monetary policy intervention have been enormous and unprecedented. The policy tool adopted by most monetary authorities around the developed world is the 
most direct amongst the three major policy tools - large scale open market purchases of bonds and gilts or quantitative easing (QE). Unlike "conventional" monetary expansions where changes in a few other economic variables may influence exchange rates as much as money supply does, the effect of QE on exchange rates and exchange rate movements greatly dwarfs that of any other economic variables. For this reason, QE effectively isolates the impact of other economic variables on exchange rate movements from that of monetary expansions, offering an immaculate environment in which the effect of monetary expansions on exchange rate adjustment and movement is studied.

The first round of QE in the US, QE1, is used for case analysis. QE1 started in December 2008 when the Federal Reserve announced it would purchase up to $\$ 100$ billion in agency debt and up to $\$ 500$ billion in agency mortgage-backed securities on November 25, 2008. Although the purchases spread over a period, that period was fairly short. The announcement effect would be also considerable, which Gagnon et al. (2010) scrutinize for QE1 in detail. The exchange rate used in the study is the US dollar effective exchange rate provided by the US Federal Reserve. The effective exchange rate is re-arranged so that an increase in it corresponds to the depreciation of the US dollar vis-à-vis the currencies of its trading partners, the same way as directly quoted bilateral exchange rates. Figure 4 exhibits US dollar effective exchange rate movements since the start of QE1 in a one-year frame, by which time the rest of the developed economies had also begun implementing their own QE programs and their asset purchases became sizeable. For example, the MPC of the UK announced a $£ 75 \mathrm{~b}$ asset purchase plan over a three-month period in March 2009; by the November MPC meeting asset purchases were extended to $f^{200 b}$ ( $c f$. Joyce et al. 2011 for the design and operation of QE in the UK). During this period, the ECB also adopted some kind of QE, albeit on a much smaller scale, including a €60b corporate bond purchase program made known in May 2009. Observing Figure 4, US dollar effective exchange rate movements in QE1 fit the 
theoretical curve delicately well. The US dollar effective exchange rate increased from an index number of around 118 at the beginning of December in 2008 to 129 by the middle of the month, causing 9 percent depreciation. Then the US dollar embarked on a reverse movement course and on March 9, 2009, the index decreased to less than 116, amounting to more than 11 percent of accumulated appreciation in nearly a quarter time period. Afterwards, the US dollar kept depreciating and by December 2009, the US dollar effective exchange rate reached 140. The US dollar depreciated by nearly 19 percent relative to its position a year ago, measured by its effective exchange rate. There are two periods when the exchange rate deviates from the evolution path on the theoretical curve. One is around the end of March 2009 when the Bank of England, following the announcement on March 5, purchased its first large chunk of corporate bonds, lasting for three weeks. This seems to be a counter effect of QE by other economies; the US dollar exchange rate stopped monotonic rising but fluctuated, for about three weeks. The second period is the end of May and June 2009, which coincided the move of the ECB and reflected another counter effect of QE in other economies. These deviations, contributed by other economies' QE, are fairly modest nonetheless.

\section{\{Figure 4$\}$}

It has been observed that the US dollar depreciated upon the expansion of money supply, but there were no signs of overshooting of exchange rates. The initial depreciation was pulsating for actual asset purchases as well as for the announcement. This kind of initial depreciation following an expansionary monetary policy is prevalent in the empirical literature, featured largely by undershooting of exchange rates, but alluded implicitly by the palpable failure to endorse exchange rate overshooting as well. Reverse movements of the exchange rate in the short-term, however, were manifest in 
QE. The US dollar depreciated inevitably afterwards in the long-run and the exchange rate moved inevitably in a depreciating manner. The displayed pattern in US dollar effective exchange rate adjustments and movements mirror the theoretical analysis of this paper remarkably agreeably.

\section{Summary}

A model of exchange rate adjustments in a dynamic IS-LM-X analytical framework has been proposed in this paper, to analyze the adjustment and evolution path of the exchange rate following a change in money supply. The proposed model firstly makes the IS-LM model dynamic, and then endogenizes the exchange rate and price variables. It extends the dynamic IS and LM components into the external sector in an open economy that evolves continuously. Effects of IRP and PPP can be and are scrutinized with this analytical framework as time goes by.

It can be observed that, following an expansionary monetary policy, the domestic currency appreciates initially after the shock, prior to gradual depreciation towards its new long-run equilibrium level that is the pre monetary expansion equilibrium rate plus the percentage increase in money supply. This pattern in exchange rate adjustments and movements is resulted from the joint and sequential effects of IRP and PPP. This pattern in the evolution path of exchange rate adjustments and movements has manifested by the recent example of the US QE in one of the most rattling epochs of the last financial crisis. The actual exchange rate movements fit the theoretical curve delicately well.

\section{References}

Anderson, B., Hammond, P.J. and Ramezani, C.A. (2010), Affine models of the joint dynamics of exchange rates and interest rates, Journal of Financial and Quantitative Analysis 45, 1341-1365. 
Auboin, M. and Ruta, M. (2011), The relationship between exchange rates and international trade: a review of economic literature, Staff Working Paper ERSD-201117, Economic Research and Statistics Division, World Trade Organization, Genève, Switzerland.

Bjørnland, H.C. (2009), Monetary policy and exchange rate overshooting: Dornbusch was right after all, Journal of International Economics 79, 64-77.

Branson, W.H., “Asset markets and relative prices in exchange rate determination," IIES Seminar Paper No. 66, 1976.

Cavaglia, S. (1991), Permanent and transitory components in the time series of real exchange rates, Journal of International Financial Markets, Institutions and Money 1, 1-44.

Dornbusch, R. (1976), "Expectations and exchange rate dynamics," Journal of Political Economy 84, 1161-1176.

Fleming, J.M. (1962), Domestic financial policies under fixed and floating exchange rates, IMF Staff Papers 9, 369-79.

Frankel, J.A. (1979), “On the mark: a theory of floating exchange rates based on real interest differentials," American Economic Review 69, 610-622.

Frenkel, J.A. (1976), “A monetary approach to the exchange rate: doctrinal aspects and empirical evidence," Scandinavian Journal of Economics 78, 200-224.

Gagnon, J., Raskin, M., Remache, J. and Sack, B. (2010), Large-scale asset purchases by the Federal Reserve: did they work? Quantitative Easing Conference, the Federal Reserve Bank of St. Louis.

Heinlein, R. and Krolzig, H.M. (2012), Effects of monetary policy on the US dollar/UK pound exchange rate - is there a "delayed overshooting puzzle"? Review of International Economics 20, 443-467.

Hwang, J.K. (2003), Dynamic forecasting of sticky-price monetary exchange rate model, Atlantic Economic Journal 31, 103-114. 
International Monetary Fund (2015), World Economic Outlook: Adjusting to Lower Commodity Prices, Washington, D.C..

Joyce, M., Tong, M. and Woods, R. (2011), The United Kingdom's quantitative easing policy: design, operation and impact, Quarterly Bulletin Q3, Bank of England.

Levin, J.H. (1994), On sluggish output adjustment and exchange rate dynamics, Journal of International Money and Finance 13, 447-458.

Meese, R. and K. Rogoff (1988), "Was it real? The exchange rate-interest differential relation over the modern floating-rate period," Journal of Finance 43, 933-948.

Mundell, R.A. (1963), Capital mobility and stabilization policy under fixed and flexible exchange rates, Canadian Journal of Economics and Political Science 29, 475-485.

Mussa, M. (1982), A model of exchange rate dynamics, Journal of Political Economy 90, 74104.

Verschoor, W.F.C. and Wolff, C.C.P. (2001), Exchange risk premia, expectations formation and "news" in the Mexican peso/US dollar forward exchange rate market, International Review of Financial Analysis 10, 157-174.

Wang, P.J. (2013), Reverse shooting of exchange rates, Economic Modelling 33, 71-76.

Zita, S. and Gupta, R. (2008), Modeling and forecasting the Medical-Rand exchange rate, ICFAI Journal of Monetary Economics 6, 63-90.

\section{Endnotes}

\footnotetext{
${ }^{1}$ In relativity, other economies' interest rates converge/revert to the domestic interest rate for a large open economy, while the latter reverts to its own long-run equilibrium rate.

${ }^{2}$ In the literature, the real interest rate is assumed to be equalized across countries in some studies, in particular in the derivation of IFE in textbooks; some others take the stance that real interest rates vary across countries and over time. We assume the latter in this study.
} 


\section{Appendix A}

Take a first order derivative and set it to zero:

$$
\frac{d\left(e^{-\frac{\beta}{\delta} t}-e^{-\varphi t}\right)}{d t}=\varphi e^{-\varphi t}-\frac{\beta}{\delta} e^{-\frac{\beta}{\delta} t}=0
$$

It reaches a minimum or maximum at time $t_{m}$ :

$$
t_{m}=\frac{\operatorname{Ln}\left(\frac{\beta}{\delta \varphi}\right)}{\frac{\beta}{\delta}-\varphi}
$$

Note $\operatorname{Ln}\left(\frac{\beta}{\delta \varphi}\right)>0$ when $\frac{\beta}{\delta}>\varphi$ and $\operatorname{Ln}\left(\frac{\beta}{\delta \varphi}\right)<0$ when $\frac{\beta}{\delta}<\varphi$, so the sign of the numerate and the sign of the denominator are always the same, $t_{m}$ being guaranteed to be positive, definite. So $t_{m} \in \mathbb{R}_{++}$and is always viable. At $t=t_{m}$, the second order derivative is:

$$
\begin{aligned}
& \left.\frac{d^{2}\left(e^{-\frac{\beta}{\delta} t}-e^{-\varphi t}\right)}{d t^{2}}\right|_{t=t_{m}}=\left(\frac{\beta}{\delta}\right)^{2} e^{-\frac{\beta}{\delta} \frac{L\left(\frac{\beta}{\delta \varphi}\right)}{\delta}-\varphi}-\varphi^{2} e^{\left.-\varphi \frac{L n}{\frac{\beta}{\delta}-\varphi} \frac{\beta}{\delta \varphi}\right)} \\
& =e^{-\frac{\beta}{\delta} \frac{\operatorname{Ln}\left(\frac{\beta}{\delta \varphi}\right)}{\frac{\beta}{\delta}-\varphi}}\left[\left(\frac{\beta}{\delta}\right)^{2}-\varphi^{2} e^{\left.\left(\frac{\beta}{\delta}-\varphi\right) \frac{\operatorname{Ln}\left(\frac{\beta}{\delta \varphi}\right)}{\frac{\beta}{\delta}-\varphi}\right]}\right] \\
& =e^{-\frac{\beta}{\delta} \frac{\operatorname{Ln}\left(\frac{\beta}{\delta \varphi}\right)}{\delta}-\varphi}\left[\left(\frac{\beta}{\delta}\right)^{2}-\varphi^{2} e^{\left.\operatorname{Ln}\left(\frac{\beta}{\delta \varphi}\right)\right]}\right]=e^{-\frac{\beta}{\delta} \frac{\operatorname{Ln}\left(\frac{\beta}{\delta \varphi}\right)}{\delta}-\varphi} \varphi^{2}\left[\left(\frac{\beta}{\delta \varphi}\right)^{2}-e^{L n\left(\frac{\beta}{\delta \varphi}\right)}\right]
\end{aligned}
$$

Therefore, whether the second order derivative is positive or negative is decided by the sign of $\left(\frac{\beta}{\delta \varphi}\right)^{2}-e^{L n\left(\frac{\beta}{\delta \varphi}\right)}$. Since: 


$$
2 \operatorname{Ln}\left(\frac{\beta}{\delta \varphi}\right)\left\{\begin{array}{l}
>\left.\operatorname{Ln}\left(\frac{\beta}{\delta \varphi}\right)\right|_{\frac{\beta}{\delta}>\varphi} \\
<\left.\operatorname{Ln}\left(\frac{\beta}{\delta \varphi}\right)\right|_{\frac{\beta}{\delta}<\varphi}
\end{array}\right.
$$

Therefore:

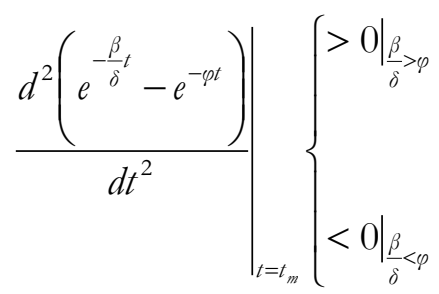

That is, $e^{-\frac{\beta}{\delta} t}-e^{-\varphi t}$ is concave for $\frac{\beta}{\delta}>\varphi$ and $e^{-\frac{\beta}{\delta} t}-e^{-\varphi t}$ is convex for $\frac{\beta}{\delta}<\varphi$.

So the fourth term of equation (14) $\frac{\frac{\beta}{\delta}-\varphi+\frac{\gamma}{\delta \lambda}}{\frac{\beta}{\delta}-\varphi} d m\left(e^{-\frac{\beta}{\delta} t}-e^{-\varphi t}\right)$ is always concave, given that $\frac{\frac{\beta}{\delta}-\varphi+\frac{\gamma}{\delta \lambda}}{\frac{\beta}{\delta}-\varphi}>0$ if $\frac{\beta}{\delta}>\varphi$ and $\frac{\frac{\beta}{\delta}-\varphi+\frac{\gamma}{\delta \lambda}}{\frac{\beta}{\delta}-\varphi}<0$ if $\frac{\beta}{\delta}<\varphi$.

When $\varphi=\frac{\beta}{\delta}$, the above analysis does not hold, where $\frac{e^{-\frac{\beta}{\delta} t}-e^{-\varphi t}}{\frac{\beta}{\delta}-\varphi}=\frac{0}{0}$. For $\varphi=\frac{\beta}{\delta}, \frac{e^{-\frac{\beta}{\delta} t}-e^{-\varphi t}}{\frac{\beta}{\delta}-\varphi}$

takes the form of:

$$
\operatorname{Lim}_{\varphi \rightarrow \frac{\beta}{\delta}}\left(\frac{e^{-\frac{\beta}{\delta} t}-e^{-\varphi t}}{\frac{\beta}{\delta}-\varphi}\right)=\operatorname{Lim}_{\varphi \rightarrow \frac{\beta}{\delta}}\left(\frac{t e^{-\varphi t}}{-1}\right)=-t \cdot e^{-\varphi t}=-t \cdot e^{-\frac{\beta}{\delta} t}
$$

Take the first order derivative and set it to zero:

$$
\frac{d\left(-t e^{-\varphi t}\right)}{d t}=e^{-\varphi t}(\varphi t-1)=0
$$

It reaches a minimum or maximum at time $t_{m}$ : 


$$
t_{m}=\frac{1}{\varphi}
$$

At $t=t_{m}$, the second order derivative is:

$$
\left.\frac{d^{2}\left(t e^{-\varphi t}\right)}{d t^{2}}\right|_{t=t_{m}}=\varphi e^{-\varphi \frac{1}{\varphi}}\left(2-\varphi \frac{1}{\varphi}\right)=\varphi e^{-1}>0
$$

Therefore, fourth term of equation (14) $\frac{\frac{\beta}{\delta}-\varphi+\frac{\gamma}{\delta \lambda}}{\frac{\beta}{\delta}-\varphi} d m\left(e^{-\frac{\beta}{\delta} t}-e^{-\varphi t}\right)$ is always concave when $_{\varphi}=\frac{\beta}{\delta}$.

\section{Appendix B}

Express equation (14) in a condensed way:

$$
\left.e(t)=e(0)+d m+\left[e\left(0^{+}\right)-e(0)+(\Psi-1) d m\right]\right]^{-\frac{\beta}{\delta} t}-\Psi \cdot d m \cdot e^{-\varphi t}, \forall t \geq t\left(0^{+}\right)
$$

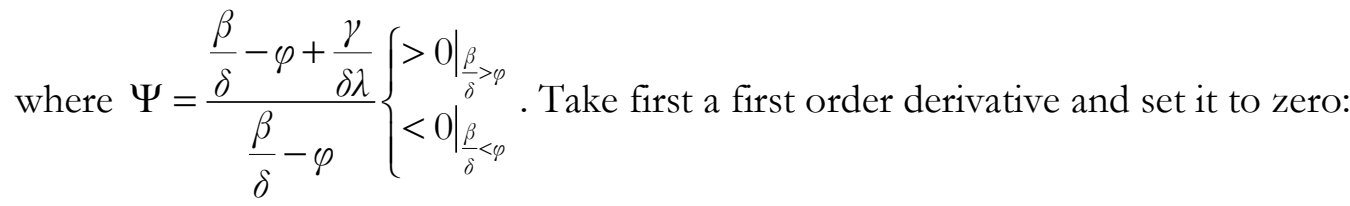

$$
\frac{d e(t)}{d t}=\varphi \cdot \Psi \cdot d m \cdot e^{-\varphi t}-\frac{\beta}{\delta}\left[e\left(0^{+}\right)-e(0)+(\Psi-1) d m\right] e^{-\frac{\beta}{\delta} t}=0
$$

The exchange rate reaches a minimum or maximum value at $t_{m}$, which can be solved by:

$$
t_{m}=\frac{\operatorname{Ln}\left[\frac{e\left(0^{+}\right)-e(0)+(\Psi-1) d m}{\frac{\delta \varphi}{\beta} \Psi \cdot d m}\right]}{\frac{\beta}{\delta}-\varphi}
$$

which additionally requires:

$$
e\left(0^{+}\right)-e(0)+(\Psi-1) d m>0, \forall \Psi>0
$$




$$
e\left(0^{+}\right)-e(0)+(\Psi-1) d m<0, \forall \Psi<0
$$

otherwise the trajectory would be monotonous without a turning point. It reduces to equation (A2) when $e\left(0^{+}\right)-e(0)=d m$. At $t=t_{m}$, the second order derivative of the exchange rate with respect to $t$ is:

$$
\begin{aligned}
& \left.\frac{d^{2} e(t)}{d t^{2}}\right|_{t=t_{m}}=\left(\frac{\beta}{\delta}\right)^{2}\left[e\left(0^{+}\right)-e(0)+(\Psi-1) d m\right] e^{-\frac{\beta}{\delta}} \frac{\left[n\left[\frac{e\left(0^{+}\right)-e(0)+(\Psi-1) d m}{\frac{\delta \varphi}{\beta} \Psi \cdot d m}\right]\right.}{\frac{\beta}{\delta}-\varphi} \\
& -\varphi^{2} \cdot \Psi \cdot d m \cdot e_{-\varphi}^{L n\left[\frac{e\left(0^{+}\right)-e(0)+(\Psi-1) d m}{\frac{\delta \varphi}{\beta} \Psi \cdot d m}\right]} \\
& =e^{-\frac{\beta}{\delta}\left[\frac{e n\left[0^{+}\right)-e(0)+(\Psi-1) d m}{\frac{\delta \varphi}{\beta} \Psi \cdot d m}\right]} \frac{\frac{\beta}{\delta}-\varphi}{\delta}\left(\frac{\beta}{\delta}\right)^{2}\left\{\left[e\left(0^{+}\right)-e(0)+(\Psi-1) d m\right]-\left(\frac{\varphi \delta}{\beta}\right)^{2} \Psi \cdot d m \cdot e^{\varphi \frac{\delta}{\beta}}\right\}
\end{aligned}
$$

The sign of the second order derivative is the same as the sign of $\left[e\left(0^{+}\right)-e(0)+(\Psi-1) d m\right]-\left(\frac{\varphi \delta}{\beta}\right)^{2} \Psi \cdot d m \cdot e^{\frac{\varphi}{\beta}}$. Therefore, the exchange rate reaches a minimum value at $t_{m}$ if:

$$
e\left(0^{+}\right)-e(0)>\left(\frac{\varphi \delta}{\beta}\right)^{2} \Psi \cdot d m \cdot e^{\varphi \frac{\delta}{\beta}}-(\Psi-1) d m
$$

in conjunction with equation (B4a) and equation (B4b).

When $\varphi=\frac{\beta}{\delta}$, the above analysis does not hold, where $\frac{e^{-\frac{\beta}{\delta} t}-e^{-\varphi t}}{\frac{\beta}{\delta}-\varphi}=\frac{0}{0}$. Take in the result in equation (A6), equation (14) becomes:

$$
e(t)=e(0)+d m+\left[e\left(0^{+}\right)-e(0)-d m\right] e^{-\frac{\beta}{\delta} t}-\frac{\gamma}{\delta \lambda} d m \cdot t e^{-\frac{\beta}{\delta} t}, \forall t \geq t\left(0^{+}\right)
$$


Take first a first order derivative and set it to zero:

$$
\begin{aligned}
& \frac{d e(t)}{d t}=-\frac{\beta}{\delta}\left[e\left(0^{+}\right)-e(0)-d m\right] e^{-\frac{\beta}{\delta} t}+\frac{\beta}{\delta} \frac{\gamma}{\delta \lambda} d m \cdot t \cdot e^{-\frac{\beta}{\delta} t} \\
& -\frac{\gamma}{\delta \lambda} d m \cdot e^{-\frac{\beta}{\delta} t}=0
\end{aligned}
$$

The exchange rate reaches a minimum or maximum value at $t_{m}$ :

$$
\begin{gathered}
t_{m}=\frac{\frac{\beta}{\delta}\left[e\left(0^{+}\right)-e(0)-d m\right]+\frac{\gamma}{\delta \lambda} d m}{\frac{\beta}{\delta} \frac{\gamma}{\delta \lambda} d m} \\
\frac{d^{2} e(t)}{d t^{2}}=\left(\frac{\beta}{\delta}\right)^{2}\left[e\left(0^{+}\right)-e(0)-d m\right] e^{-\frac{\beta}{\delta} t}-\left(\frac{\beta}{\delta}\right)^{2} \frac{\gamma}{\delta \lambda} d m \cdot t \cdot e^{-\frac{\beta}{\delta} t} \\
+2 \frac{\beta}{\delta} \frac{\gamma}{\delta \lambda} d m \cdot e^{-\frac{\beta}{\delta} t} \\
=\frac{\beta}{\delta} e^{-\frac{\beta}{\delta} t}\left\{\frac{\beta}{\delta}\left[e\left(0^{+}\right)-e(0)-d m\right]+2 \frac{\gamma}{\delta \lambda} d m-\frac{\beta}{\delta} \frac{\gamma}{\delta \lambda} d m \cdot t\right\}
\end{gathered}
$$


Figures

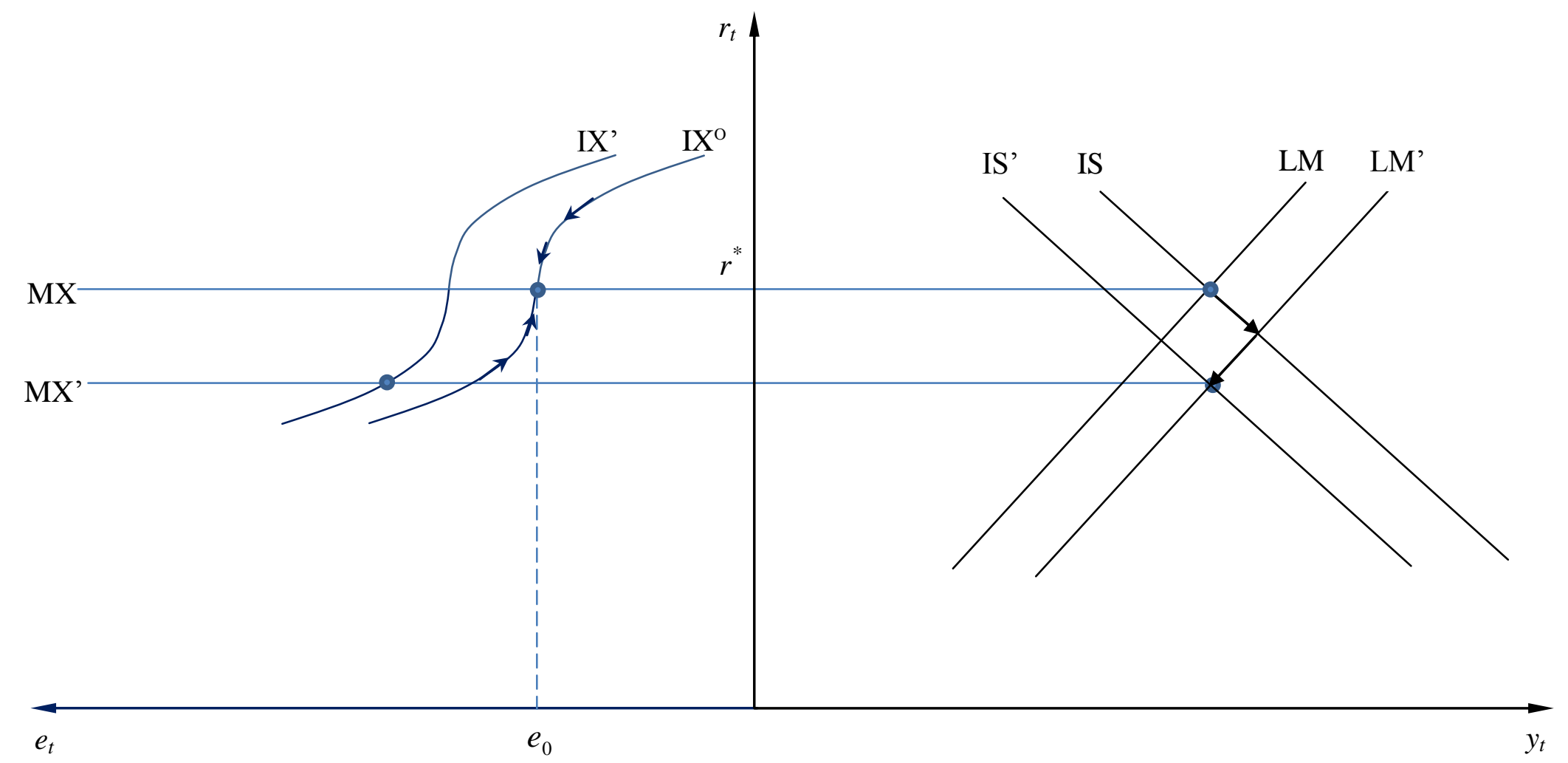

Figure 1. Dynamic IS-LM-X framework 

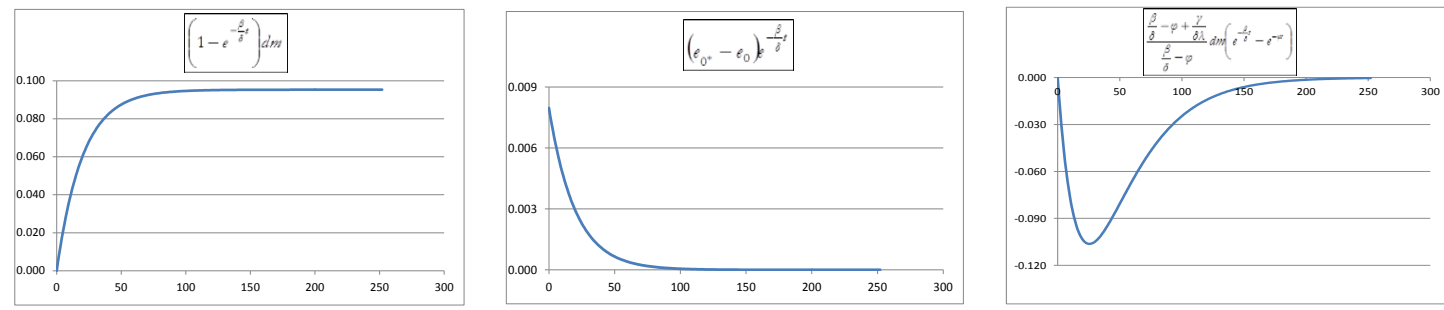

(a) Patterns in three terms

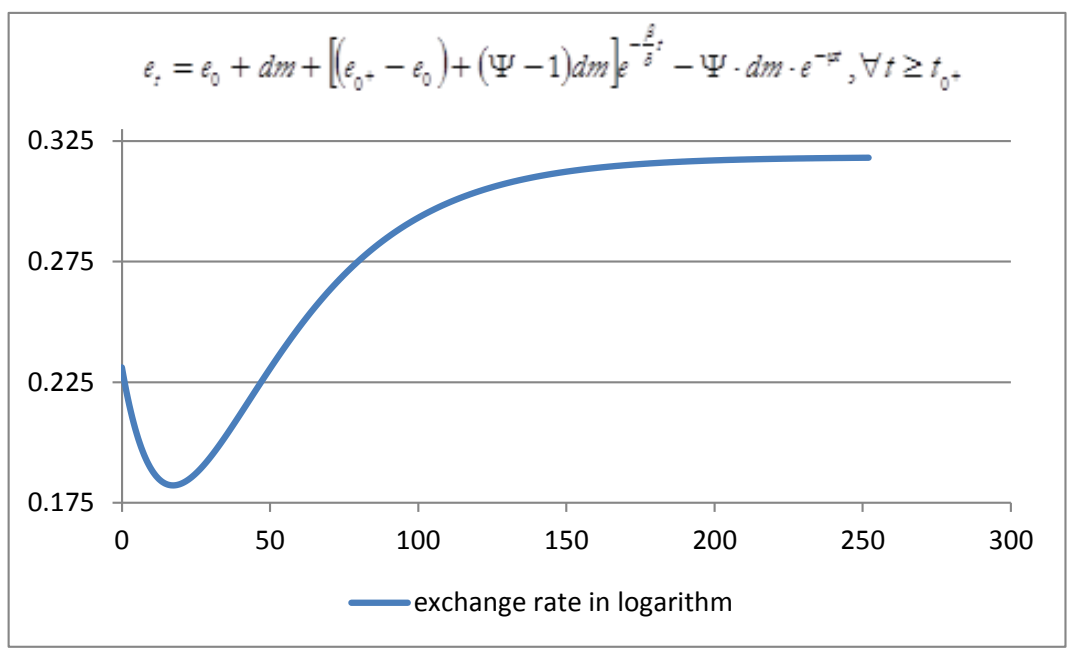

(b) Patterns in exchange rate adjustment and movement in logarithm

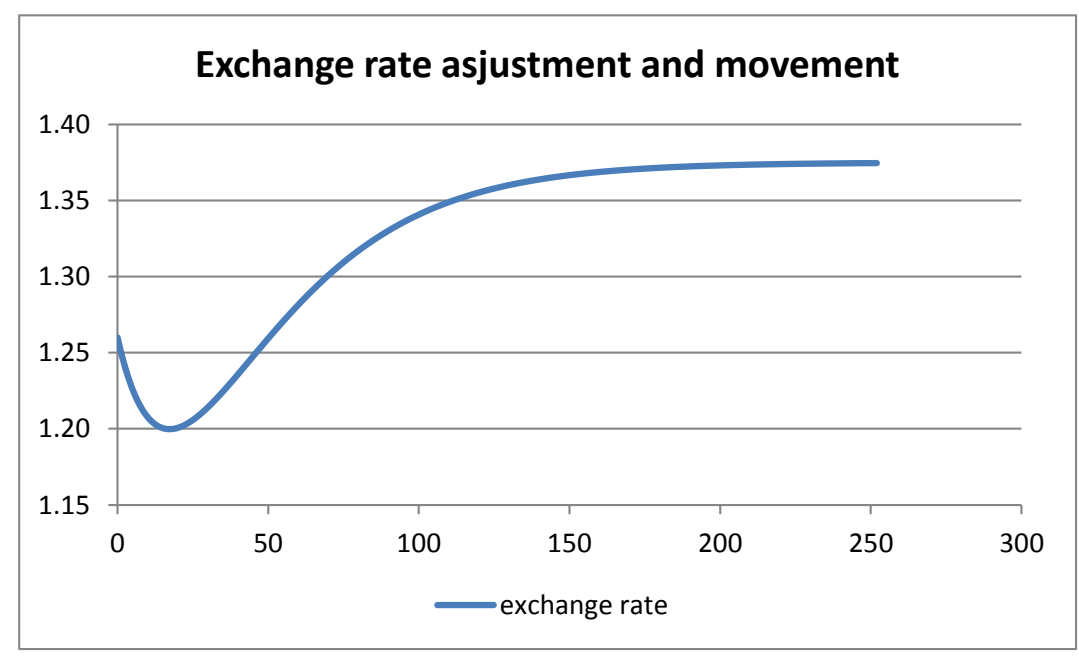

(c) Exchange rates

Figure 2. Exchange rate adjustment and movement 


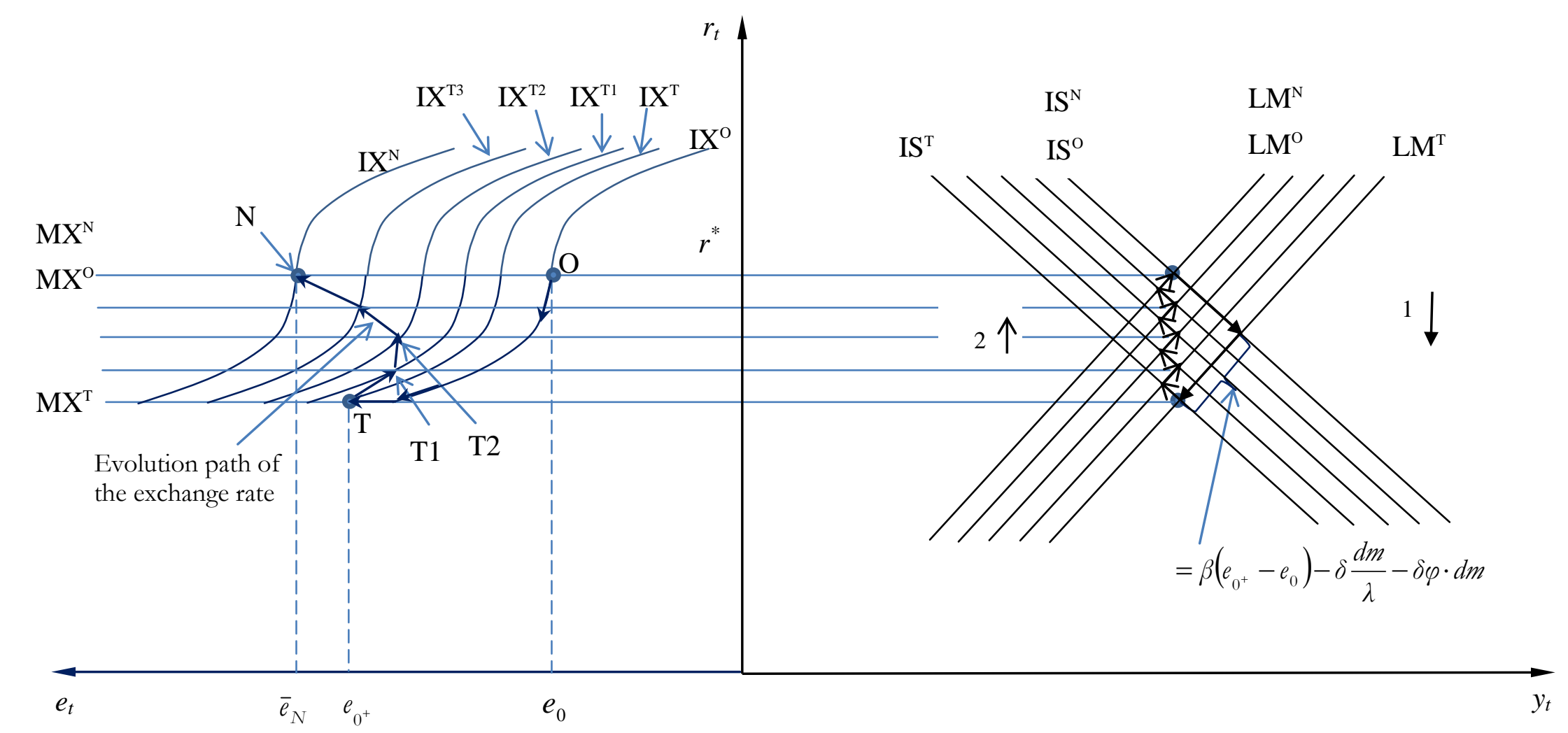

Figure 3. Path of exchange rate adjustments and movements in dynamic IS-LM-X framework 

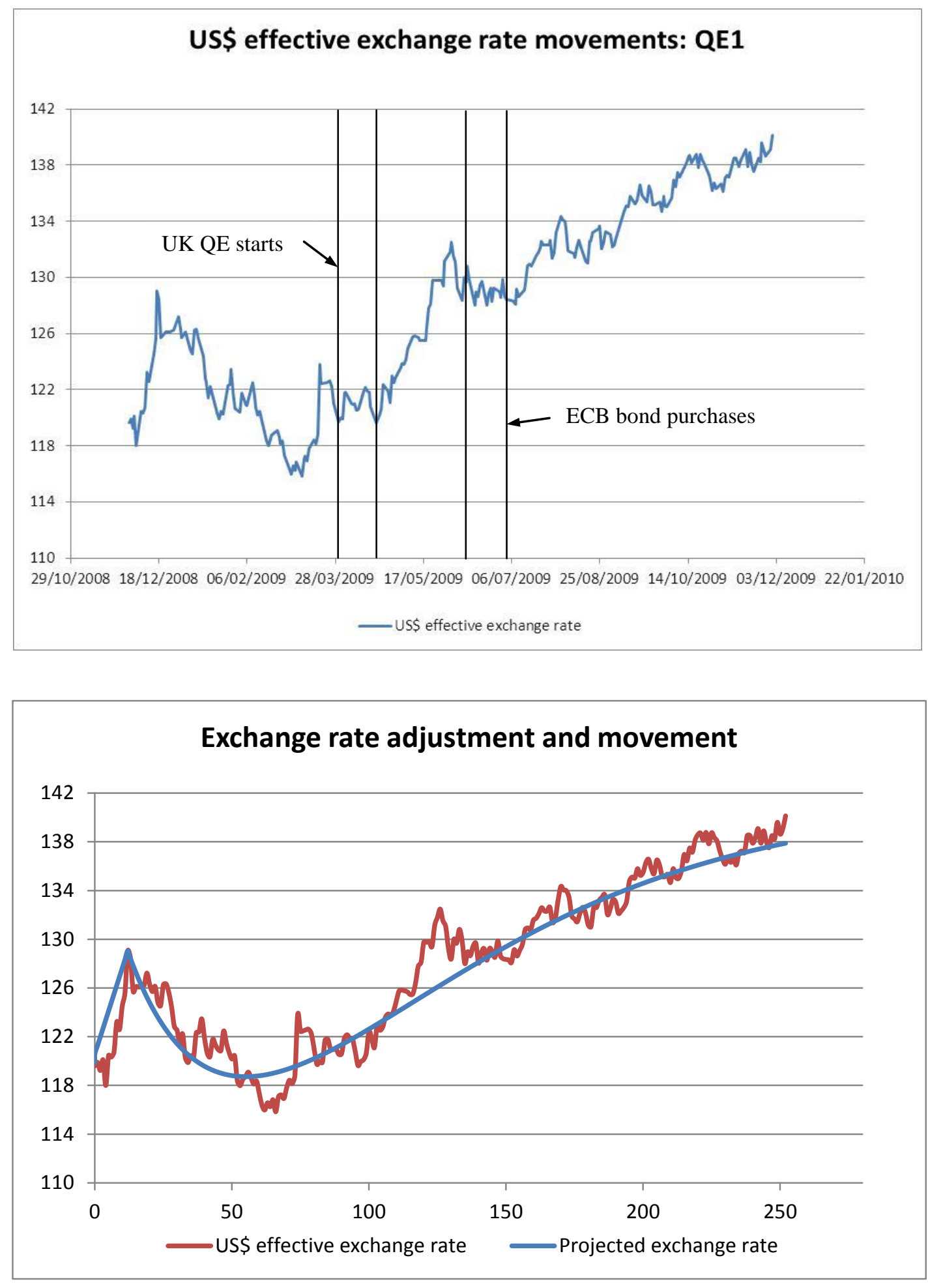

Figure 4. Exchange rate adjustments and movements: actual and projected 